\title{
Does an Environment Serving Organization Based View Support A Product Market Strategy? A Firm Performance Analysis
}

\author{
A N Oroh \\ Management Department, Universitas Bina Nusantara, Jakarta, Indonesia \\ Agustinus.Oroh@binus.ac.id
}

\begin{abstract}
This research elucidates the concealed practice of an environment serving organization (ESO) based view in an industry which enhances a firms strategic position and performance. This research infers that companies which rely more on synergistic efforts actually support their overall capabilities in gaining and sustaining a competitive advantage. Using the firm environmental turbulence and strategic aggressiveness approach, this research postulates that the product market strategic activities and internal synergistic efforts of a company should be aligned with the business environmental turbulence to achieve and ensure a more sustainable performance. The statistical findings highlight that a firm's competitivenesis built through a full understanding of the ESO-based view and combines the product market strategic aggressiveness with internal synergistic efforts. Furthermore, this study introduces the five levels of internal synergistic efforts to be considered following the statistical mediation analysis findings that internal synergistic efforts have a more mediating role than product market strategic aggressiveness in affecting the strong relationship between environmental turbulence and firm performance.
\end{abstract}

Keyword : ESO, Environmental, Product Market

\section{INTRODUCTION}

Companies believe that their superior products and ready-to-buy customers are the key success factors in building and sustaining their businesses, regardless of the marketing strategies used. The more their goods and services provide benefits to their customers, the better the firm performance, position, and competitive advantage will be.

Top management is responsible for orchestrating strategic activities in the company for positioning and relating those activities to the external market condition to ensure that optimum performance is achieved and sustainable. A synergistic effort has been repeatedly mentioned by distinguished scholars as comprising the interrelationships between strategic activities [1] and is considered a major strategic catalyst for firms to succeed [2]. However, since products and markets are the dominant factors for companies, it is still not officially common for companies to prioritize a synergistic effort. Like other aspects in management, namely core competencies, strategic resources, portfolio strategies, market and product development, market penetration, and strategic plans, a synergistic effort is just one aspect. For some companies, discussions on synergistic efforts between products, brands, and particularly business units are a waste of time and therefore avoided. On the other hand, more 
and more companies are unable to analyze and therefore anticipate their futures due to their own mistakes and lack of competencies. The concep to businessis business "does not apply any more and paralysis by analysis is the out come.

\section{LITERATURE REVIEW}

\subsection{Environment Serving Organization Based View}

Companies need to understand the industry and external market situations they are facing today to anticipate their futures. A few companies are aware they are still facing a monopolistic market condition in which whatever they produce is well received by the market, since "no" real competitors are challenging them in the market. Some companies are facing a few competitors who are selling similar products and therefore should anticipate their customers $^{\text {ee }}$ perceptions of their products and modify their products accordingly to ensure sustainable performance. Some companies realize that besides facing fierce competition from other companies to sell existing products, they also need to create and produce new products following changes in their customers ${ }^{e e}$ tastes and preferences due to technological changes and innovations as well as competitors"e retaliation.

These sensible situations have led some prominent scholars to hypothesize that for companies to gain optimum performance they need to be able to understand, prepare, and anticipate their business activities according to the market and business environment. Companies which can adjust their strategic activities and competencies according to their market and business environment will gain and sustain their financial performance and competitive advantage. Companies which only stick with their strategic knitting and develop their competencies and resources accordingly and without focusing first on knowing and following the market and business environment, will slowly but surely fail to compete and go bankrupt. This is the essence for the environment serving organization based view.

Originally the Environment-Serving-Organization (ESO) concept was mentioned and introduced by a prominent scholar and practitioner in strategic management in the aircraft industry as the organizations or firms that exist with missions to provide goods or services (products) to serve the needs of the environment (market), and their survivals are depending on the proceeds of its sales [3]. After its inception and sometime, this Environment-ServingOrganization concept was then explicitly tested at various industries and countries including in South East Asia (Indonesia) on the relationships between strategic effectiveness, competitive efficiency and firms performance [9]; in Europe (Germany) on managing transformational change in business firms [4] in North Asia (Korea) on the relationships between environmental turbulence, top manager mindset, organization culture, power and firms performance [5], and also the relationships among environmental turbulence, strategic aggressiveness of information technology, and organizational performance in Korea [6]. The results were supporting the fundamental believe of Environment-Serving-Organization based that companies would achieve their optimum performance if their strategic aggressiveness, capabilities aligned with their environmental turbulence level.

During the $90^{\text {ee }} \mathrm{s}$ Ansoff has also presented a paper stated that Environment-ServingOrganization based view has offered a strategic way-out for companies (in the United States) to prepare them to stay ahead of the competition at every turbulence level since there are usually many business units facing different market situation at the same time which require different competencies and strategies to succeed at every level [7]. Complementing the paradigm of strategic planning, in his article on strategic choices, another prominent scholar in 
strategic management [8] said that in order to stay ahead of competition, management team should gather some basic background information on the changes in the business environment and to stay consistent internally, externally and dynamic to devise a number of viable options, not a single course of action to face any situation in the business environment. This is basically aligning and supporting the fundamental concept of Environment- ServingOrganization where company must have strategic options to face any turbulence level or changing marketsituation.

In this paper, starting with product and market definitions, writer would like to elaborate that the concept of Environment-Serving-Organization was basically the root of productmarket strategies developed further by Ansoff (called Ansoff Matrix) and then been using by many business textbooks, researchers, prominent scholars, and last but not least using by many companies until today. However, for company"s strategic reasons, maybe, this concept will not be put as popular as the resources-based and positioning-based views as some current strategic management literature stated.

\subsection{Product and Market Definitions}

Ingeneralterms, thewords'product' and 'market'havetheirownmeanings. AccordingtoMerriamWebster"s Collegiate Dictionary (2003),A product is something produced and something that is marketed or sold as a commodity. A market, on the other hand, refers to a meeting together of people for the purpose of trade by private purchase and sale and usually not by auction. A market is also a geographic area of demand for commodities and services. One argument is if people like the commodity at a convenient and preferred geographic area, only then will they purchase theproduct.

Prominent researchers use the product market as a strategy in winning market shares and building a competitive advantage [9], [7]. However, a firm can suffer from confusion in strategy implementation and mediocre performance if it attempts to combine cost leadership and marketing differentiation [10], [1]. Thus, the context of a product-market strategy should be clearly understood prior to using it as a company"s strategy.

In using the performance analysis and the environment serving organization based view, this paper starts with investigating some scholar argumentations on product-market strategic aggressiveness, environmental turbulence, and synergistic efforts from employees ${ }^{\text {ee }}$ perspectives in order to devise comprehensive inputs for companies to adopt a new way of managing their activities and to anticipate future business and market changes. This is important especially when information is very transparent for customers, so that company strategic activities and resources can be duplicated without difficulty, and even technology inventions can be reproducedeasily.

\subsection{Product Market Strategic Aggressiveness}

In general, the term 'aggressiveness'refers to a disposition or characteristic to dominate often in disregard of another"s rights or in a determined and energetic pursuit of one's ends (MerriamWebster"s Collegiate Dictionary, 2003). As a matter of fact, companies need to be aggressive to compete and dominate the market and industry. The issues are what should be the right strategy, how far a company should pursue a particular strategy, and also to ensure a company does not violate an ethical boundary since a business is not only about making a shorttermprofit.

In a product market research context, scholars discover that product market uncertainty 
using a resource based view is associated with portfolio restructuring actions and then influenced by performance [11]. Product-market extensions, in general, bestow valueenhancing opportunities [12]. Marketing differentiation and cost leadership strategies positively influence differentiation and cost advantages, respectively [13]. Architectural and specialized marketing capabilities, and their combination, positively mediate the productmarket strategy and origin of the business unit performance correlation [14]. The fit between the strategic resources of marketing organizations and product-market strategy promotes superior financial and customer market performance [15].

More than half a century ago Ansoff [16] published an article while he was the Director of Lockheed Corporation and stated that a "product-market" strategy is the formula of the product line $\pi \mathrm{i}$ and the corresponding format of the market (or mission of the product it is produced for) $\mu \mathrm{j}$. Therefore, the product market is $\sigma \mathrm{ij}$ : $(\pi \mathrm{i}, \mu \mathrm{j})$. So, it can be inferred that a product is made for a mission to satisfy its buyers. As a result, the meaning is much larger than in a market where people buy the product. Ansoff formulated it further in a matrix called the Ansoff Matrix, which consists of four different activities depending on the condition of the product and market or missions of the company, whether the product or service is an existing or a new product set up for an existing or new market situation or target. Each box in the matrix has its own meaning and purpose i.e. an existing product of an existing market (market penetration), an existing product of a new market (market development), a new product of an existing market (product development), and a new product in a new market (diversification). Thus, there are four product market strategies, namely market penetration, market development, product development, and diversification. However, Ansoff did not stop at that description. He argued that we, especially business managers and practitioners, should understand

the contextofthoseboxesinthematrix. Thesefourstrategiesalongwiththegeographicalandtechnologica 1 aspects are part of other key strategic factors of a company when relating those strategies into every market or businessenvironment.

In strengthening the above viewpoint, researchers in several countries revealed that Ansoff"s matrix product market strategies have strategic relationships with a company"s growth performance. In Kenya, Africa, the soft drink industrial market indicates that market penetration strategies have a relationship with organizational growth, while there is a weak positive relationship between product development or improvement strategies and organizational growth. The researcher further argued that all four product market strategies indeed complement each other to increase a company"s performance [17]. In Pakistan, the fast food sector reveals that out of four product market strategies, the diversification strategy showed a negative correlation with a company"s growth, while other strategies revealed positive relationships [9]. In the United States, the mutual fund industry shows that experience breadth in a new product development strategy benefits firms [18]

\subsection{Environmental Turbulence}

In Merriam-Webster"s Collegiate Dictionary (2003) „turbulence" means the quality of being turbulent, while „turbulent" is causing unrest, violence, or a disturbance, or characterized by agitation (shakeup, disturbance, stir, anxiety, nervousness) or tumult (turmoil, confusion, chaos, disorder). History has revealed that not only during a physical world war could a huge turbulence happen, but also during an economic boom some of the so-called good companies faced the highest turbulence in their lives when they could not compete anymore due to the occurrence of unexpected and therefore unplanned situations. 
Strategic management scholars have described environmental turbulence as a joint measure of changeability and predictability of the company"s environment [7] [19]. Like the definition of a market, environmental turbulence is an external variable which focuses on change, whose values specify the type of behavior necessary for success. It is described by five different turbulence levels in the environment serving organization based concept [7]. Each level of turbulence needs specific resources like strategic capabilities and behaviors. At the same time, the resource based view conveys that the controlled internal resources and capabilities should be the fundamentals of business success. Therefore, firm resources have to be valuable, rare, costly to imitate, and non-substitutable economies of scale, learning curve economies, as well as have access to low-cost factors of production and technological resources [20], [8], [21]. These two concepts, environment serving organization based and resource based, focus on the external unpredictable and internal adjustments, while the other from the internal and controllable perspective indeed complement and strengthen eachother.

The environment serving organization based (ESO) view puts forth the concept that to optimize and sustain its overall performance, companies should always align their strategic aggressiveness and management capabilities to the relevant business environment today and in the future. The first action is to analyze and understand the current and future business environment. As a matter of fact, the world has been moving and changing rapidly, and technology is the absolute driving force and key success factor, as everything can be imitated relatively easier and faster thanbefore.

Following the ESO-based view, the business environment at level one reflects a situation of a very efficient business transaction. Nothing changes from the previous condition without any turbulence, and if there is a change, it will be indeed be slow. Therefore, it can be acted upon relatively easily by companies. At level two, the change is still slow. However, it occurs more frequently, as the company can respond properly on time before any surprise materializes. At a higher level, three, the alteration becomes faster, but the future is still a reasonable extension of a historical precedent, so companies can foresee and prepare an event before theshock.

Researchers stated that companies must have a forward-looking strategy, in which the responses can be planned earlier. Therefore, the companies should be ready to cope with the turbulence. At level four, when the alteration is not only rapid but also comes and goes at an unpredicted cycle, companies must have not only a forward looking strategy, but also an environmental scanning system should bein place to prepare strategic actions and reactions. At level five, changes move so fast and also the future is unforeseen. It is very complicated to foresee what will take place in the future. Companies should create a market and prepare to surprise their rivals.

Other turbulence concepts come from the marketing paradigm of market turbulence, competitive intensity, and technological turbulence from the Market Orientation Model [22] [23]. Market turbulence basically measures the tendency or the real changes of the customers ${ }^{\text {ee }}$ preferences over time. Competitive intensity assesses the behavior, resources, and ability of competitors to distinguish their strategies. Then technological turbulence items exploit the degree to which technology in an industry is changing. For some industries today, the invention of new technology is the driving force to succeed. So, if these technology-driven companies fail to invent, their performances will be in trouble, if notbankrupt.

Earlier research by Miller et al. (1983) postulated the extent to which changes in environmental challenges are actually correlated with changes in strategy making in order to achieve a high level of performance. Companies should change their strategies if they are going to perform better than their competitors at a given change in the environment. They 
were quoted from other scholars that there are at least three variables of environmental categories, e.g. dynamism or uncertainty, hostility or unfriendliness, and heterogeneity or complexity. Each needs a different degree of internal changes and strategies.

Again, the fundamental of the above mentioned environment serving organization based view is aligned with another prominent scholars definition of competitive advantage, who stated that a firm which is able to produce more economic value than its competitors gains a competitive advantage in its product market [24]. This can be referred back to Ansoff's product market growth strategies in the Ansoff Matrix Model which was explained earlier and includes market penetration, market development, product development, and diversificationstrategies.

From the above arguments, it can be hypothesized that there are strong correlations between environmental turbulence with firm performance. The more turbulence that is found in the environment, the more effort is needed by the firm to take action to ensure its performance sustainability. In general, firms which change and adjust their activities to the general turbulent situation in the market will perform better (H1). Furthermore, the more sensitive and therefore distinctive the firm activities are to every turbulent level, the better the performance will be compared to the "general" adjusted firms which have adjusted their activities but are not aware of the level of each turbulence (H2).

\subsection{Internal Synergistic Effort}

Previous research on product market uncertainty revealed that companies which restructured to lower information-processing costs and raise internal synergy had the highest financial performance [11]. A research study in manufacturing companies in Indonesia revealed that synergy has shown a positive effect to firm"s performance and then a mediating role of the strong relationship between strategic planningandfirm"sperformance [24]. However,ingeneralnotmanystudieson strategicmanagement have given enough attention to the real benefits of internal synergistic efforts, but more on the external variables like mergers andacquisitions.

Using the concepts of scholars on an ESO-based view, especially on the five levels of optimum general management capability profiles [7], different growth stages need different focuses [17], and then in the four strategic planning dimensions [25], it is argued that not only should a plan be opened to adaptation and change as the implementation proceeds, but also internal synergistic efforts are needed to be adjusted according to the environmental turbulence level.

Following the above argument and referring to the concept of managerial cognitive capability which emphasizes capabilities on physical and mental activities [8], and in the context of the environment serving organization based theory [2], [7], strategic synergy efforts can then be categorized from level one-cooperative stability seeking, level two-cooperative efficiency seeking, level three - cooperative growth seeking, level four - cooperative opportunity seeking, and to level five- cooperative opportunity creating. Top management and key managers must be equipped with these capabilities and mindsets in order for their firms to really gain and sustain a competitive advantage regardless of their market positions, but they should be consistent with the environmental turbulence level.

It is proposed that in a turbulent environment at level one where a business is steady, no weak signal appears in the industry to be worried about, and competition is not intense. The hypothetical synergy mentality needed is synergy with stability seeking. Top management and key managers focus on how to ensure stability in the companies. There will be "no specific 
pressure" to enforce synergy between departments and business units. Business as usual is the mindset. Therefore, at level one stability seeking should be the key manager"s synergy mentality. The question is whether any level one markets still prevail.

In a turbulent environment at level two when a business is no longer steady, a weak signal appears, slow changes come up, and competition starts, companies need to focus on how to reduce their costs. Therefore, hypothetically the synergy mentality needed is efficiency seeking to increase competitiveness. Working together better to increase operationa lperformance should be the manager"s mentality. In a turbulent environment at level three when a customer"s preferences and tastes are shifting, the speed of changes are faster than before due to a larger global market, and competitors easilyfolloweachother"sstrategies. Companies need to shift their priorities to grow better than their competitors. Top management and key managers adjust their strategies to be more market focused than ever before. Thus, hypothetically the mindset will be how to ensure growth by working together better and being smarter.

In a turbulent environment at level four when top management and key managers can still foresee predictable changes happening in the industry, companies need to establish opportunities by enhancing departments and business units to work together and observe what happens outside their comfort zones. It is obvious that this mentality can easily be found in top performance companies with strong cooperation between the research and development team and the marketing and production team. Thus, hypothetically the key managers must focus on how to orchestrate cooperation as much as possible to seek opportunities or markets and relatedchanges.

In a turbulent environment at level five where not only changes in the industry are unpredictable and discontinuous but also surprises in terms of new products and excellent services become the rules of the game and the business as usual, companies need to invent opportunities or create markets and therefore initiate changes by ensuring all departments and business units are working together, and then creating novel and innovative products or services to stay competitive.

\subsection{FirmPerformance}

Many scholars have argued that combinations of financial and non-financial indicators should be the fundamental measuring sticks to measure a company"s real performance. There are many aspects not covered by financial numbers to indicate a good performing company, for example, how many profitable new products can be launched in a year or in a certain period of time. Therefore, this research uses a relevant questionnaire which covers these nonfinancial indicators accordingly.

Since this research focuses mainly on the internal and operational activities, previous research is used in supply chain integration to ensure that the firm performance indicators are relevant to reflect the relationship between the independent variables (which are environmental turbulence, product market strategic aggressiveness, and internal synergistic effort) and the dependent variable (which is firm performance). Accordingly, operational performance and business performance indicators are applied, such a show fast acompany can modify its products to be able to meet its majo rcustomers" requirements and therefore earn the customers "loyalty to the company"s products, how quickly a company can introduce new products into the market to fulfill customers ${ }^{e e}$ needs, and so on, as wellasincrease the company"s growth in sales compared to its major competitors, improve its growth in profit compared to its major competitors, and so on [4]. 
Following the above statements, it can be hypothesized that different turbulent environments need different kinds of product market strategic approaches and internal synergistic efforts. The more turbulent the environment is, the more relevant those two variables will be. A relevant product market strategy and internal synergy will affect the maximum firm performance level. The more turbulent the environment is, the lower the firm performance level will be, unless the firm can match the environmental turbulence, product market strategic aggressiveness, and internal synergistic effort level, regardless of which level of business turbulence the company is facing. The more turbulent the environment is, the more synergistic efforts are needed in choosing the right product market strategy to maintain firm performance. Greater turbulence in the environment will lead to more "calculated risk" product market strategies utilized by a firm to optimize itsperformance.

Furthermore, it can also be hypothesized that product market strategic aggressiveness shows a mediating variable role in the relationship between environmental turbulence and firm performance. The same with an internal synergistic effort, this variable shows a similar role. Firm performance may be better with both mediating variables.

\section{METHOD}

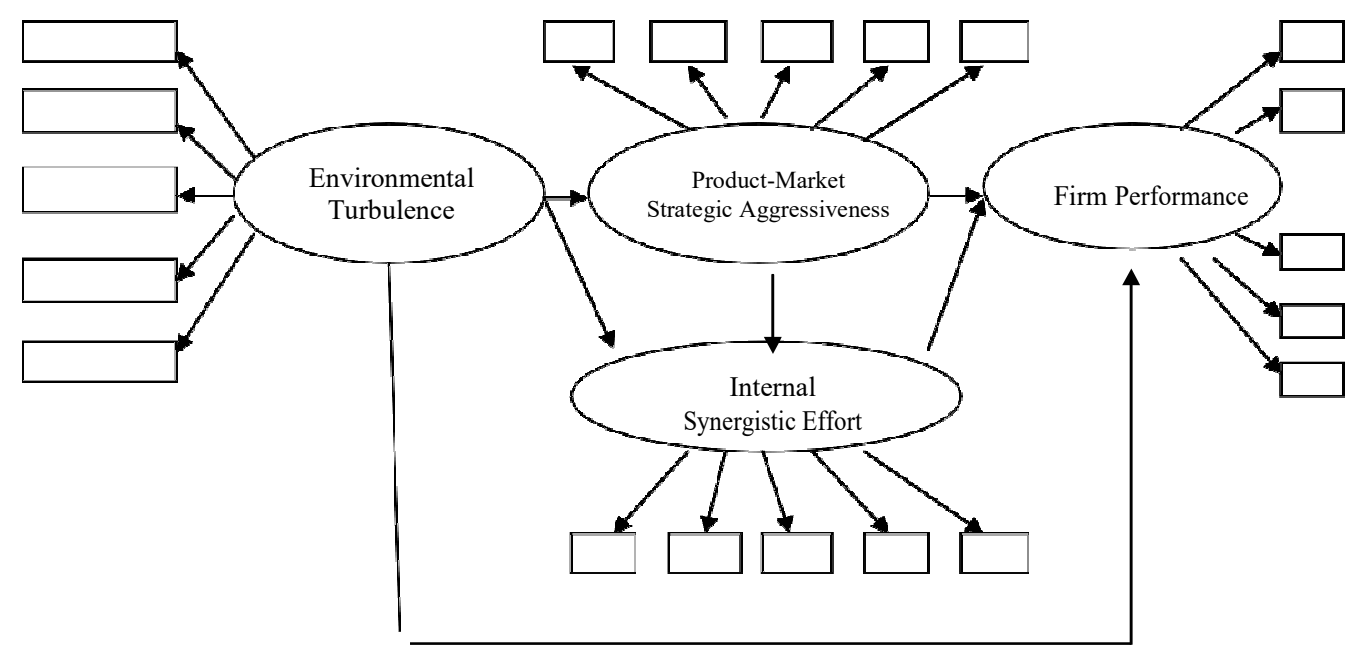

Figure 1. Research Model/Framework.

The research applied recommended and well managed companies in Indonesia with the understanding that they represented industries with different economic situations to reflect distinctive actions on turbulence. Following research in China where informants were selected in each of the company"s divisions to ensure these selected representatives were really aware of the company"s business and market environments [26], communication was conducted with Head of Human Capital to crosscheck their existence was indeed true. Thus, discussions were carried out with senior general managers, senior vice presidents, CEOs, and COOs of the selectedcompanies.

Furthermore, not only a qualitative method was used by conducting in-depth interviews with those selected representatives but also a main quantitative method was applied by processing the collecteddata from questionnaires of more than 200 respondents who were 
working at those major fast moving consumer goods multinational companies, automotive and chemical companies, and pulp and paper multinational companies in Indonesia.

Following the arguments and hypotheses as well as the research model, questionnaires were prepared to recognize and determine quantitatively all the variables including productmarket strategic aggressiveness, environmental turbulence, internal synergistic efforts, and firm performance. In general, a Likert scale was used from 1 "strongly disagreed or poor" to 5 "strongly agreed or extensive" to measure those questions. Questionnaires were emailed to more than 500 top management representatives and their top managers, who included senior managers, general managers, and the director"s level of those mentioned companies in Indonesia. A pre-test was done prior to sending those questionnaires to ensure that all the respondents clearly understood the meaning of each question by asking them directly in emails, through phone calls, and during opendiscussions.

Following the research model, a simple multiple linear regression analysis was used to understand and ensure the data and framework were statistically valid and reliable as well as acceptable. Then, in order to develop the analysis and observe further, a two-stage simple mediation analysis using IBM SPSS was employed, in which the variables were arranged in a predictive causal path model to assess the dynamics of their relationship [27]. In analyzing the mediating roles, a two-stage analysis was carried out. In the first stage, an investigation was conducted on the mediating role of the product market strategic aggressiveness variable on the relationship between environmental turbulence and firm performance variables. Then it examined whether the internal synergistic effort indeed showed a mediating role, and which of the two variables actually had a more mediating role on the significant relationship of environmental turbulence on firmperformance.

\section{RESULTS AND DISCUSSION}

Based on the statistical results (Appendix A and Appendix B at next pages) it can be inferred and stated that not only the indicators used to measure the variables are reliable and valid but also the data and research model used and presented in the study are statistically acceptable and significant. There are significant correlations between the three independent variables on firm performance as the dependent variable. Environmental turbulence, product market strategic aggressiveness, and internal synergistic efforts are shown to have significant and strong correlations with firm performance. This is to confirm that the three independent variables have important roles regarding firm performance. The more aggressive the product market strategies and synergistic efforts are that are then aligned with the market and consumers" needs, the better its performance will be.Thisre inforces the theory developed by Ansoff (ESO-based).

Environmental turbulence is shown to have a positive and significant correlation with firm performance. Both product market strategic aggressiveness and internal synergistic efforts have moderating effects on the firm performance in a way that affects the correlation path ${ }^{\text {ee }} \mathrm{s}$ strength onthe firm performance. Internal synergistic efforts have shown to have a more positive correlation and mediating role on the positive relationship of environmental turbulence and firm performance. A company which uses and shows more internal synergistic efforts will have a better firm performance. Furthermore, a similar mediating role has been found from product-market strategic aggressiveness correlated with firm performance. Another main finding in this research is the variable internal synergistic effort has a more moderating role $(18.10 \%)$ than product market strategic aggressiveness $(8.75 \%)$ on the relationship between environmental turbulence and firmperformance. 


\subsection{Managerial Implications}

The main contribution of this research is that a company must put its focus and activities on the environmental turbulence variable of its industry and adjust its product market strategic aggressiveness and internal synergistic effort in order to optimize its performance and firmly out-compete itscompetitors. This further confirms that the environment serving organization based view is still relevant until today.

This research can be used by especially fast moving consumer goods, automotive, chemical, as well as pulp and paper companies to improve their overall performance and sustain a competitive advantage. By focusing and applying relevant internal synergistic efforts and then product-market strategic aggressiveness in a specific environmental turbulent situation that is supported by a real plan, only then can companies outperform their competitors. Following further findings, product-market strategic aggressiveness alone is not sufficient to guarantee the performance growth of a company. The company must increase its focus on internal synergistic efforts by ensuring there are capable managers who are responsible to act as synergy leaders, since synergy has its own measurements and distinctiveactivities.

\section{CONCLUTION}

Future studies should be conducted on analyzing further the real strategy of diversification as suggested by Ansoff in the Ansoff Matrix at each and every different environmental turbulence level. It will enrich further the ESO-based view and theory in the current digital era and for the future. It surely can be used by top management to complement the other productmarket strategies as part of the comprehensive strategies, since companies often face different market situations and pressures within their product and market portfolios at the same time. Thus, companies not only have to train their key people, but they should also ensure that managers and leaders grasp the fundamental knowledge and skills of the four product-market strategies to optimize the performance of the portfolio at any turbulence level.

\section{REFERENCES}

[1] L. S. Meyers, G. C. Gamst, and A. J. Guarion, Performing Data Analysis Using IBM SPSS. NewJersey: John Wiley \& Sons Inc., 2013.

[2] H. I. Ansoff and E. McDonnell, Implanting Strategic Management, 1st ed. Cambridge, U.K: Prentice Hall International, 1990.

[3] H. I. Ansoff, "Strategy Formulation as a Learning Process: An Applied Managerial Theory of Strategic Behavior," Int. Stud. Manag. Organ., vol. 7, no. 2, pp. 58-77, Jun. 1977.

[4] B. B. Flynn, B. Huo, and X. Zhao, "The impact of supply chain integration on performance: A contingency and configuration approach,”J. Oper. Manag., vol. 28, no. 1, pp. 58-71, Jan. 2010.

[5] J. F. Hair, C. M. Ringle, and M. Sarstedt, "PLS-SEM: Indeed a Silver Bullet," J. Mark. Theory Pract., vol. 19, no. 2, pp. 139-152, Apr. 2011.

[6] J. W. Rivkin, "An Options-led Approach to Making Strategic Choices Harvard Business School," 2006.

[7] H. Igor Ansoff and P. A. Sullivan, "Optimizing profitability in turbulent environments: A formula for strategic success," Long Range Plann., vol. 26, no. 5, pp. 11-23, Oct. 
1993.

[8] M. A. Peteraf, "The cornerstones of competitive advantage: A resource-based view," Strateg. Manag. J., vol. 14, no. 3, pp. 179-191, Mar. 1993.

[9] S. Hussain, J. Khattak, A. Rizwan, and M. . A. Latif, "Ansoff Matrix, Environment, and Growth - An Interactive Triangle," Manag. Adm. Sci. Rev., vol. 2, no. 3, pp. 196206, 2013.

[10] Y. W. Han, "The Relationships Between Environmental Turbulence, Top Manager Mindset, Organization Culture, Power and Performance in Korean Firms," United States International University, San Diego, California, 1999.

[11] D. D. Bergh, "Product-Market Uncertainty, Portfolio Restructuring, and Performance: An Information-processing and Resource-Based View," J. Manage., vol. 24, no. 2, pp. 135-155, Apr. 1998.

[12] K. C. Gleason, I. Mathur, and R. A. Wiggins, "The Evidence on Product-Market Diversifying Acquisitions and Joint Ventures by U.S. Banks," J. Financ. Serv. Res., vol. 29, no. 3, pp. 237-254, Jun. 2006.

[13] M. Hughes, S. L. Martin, R. E. Morgan, and M. J. Robson, "Realizing Product-Market Advantage in High-Technology International New Ventures: The Mediating Role of Ambidextrous Innovation," J. Int. Mark., vol. 18, no. 4, pp. 1-21, Dec. 2010.

[14] D. W. Vorhies, R. E. Morgan, and C. W. Autry, "Product-market strategy and the marketing capabilities of the firm: impact on market effectiveness and cash flow performance," Strateg. Manag. J., vol. 30, no. 12, pp. 1310-1334, Dec. 2009.

[15] P. Hughes and R. E. Morgan, "Fitting strategic resources with product-market strategy: Performance implications," J. Bus. Res., vol. 61, no. 4, pp. 323-331, Apr. 2008.

[16] H. I. Ansoff, “A Model for Diversification,” Manage. Sci., vol. 4, no. 4, pp. 392-414, Jul. 1958.

[17] N. G. Wainaina and M. Oloko, "Market Penetration Strategies and Organizational Growth: A Case of Soft Drink Sector in Kenya," Int. J. Manag. Commer. Innov., vol. 3, no. 2, pp. 219-227, 2016.

[18] J. P. Eggers, "All experience is not created equal: learning, adapting, and focusing in product portfolio management," Strateg. Manag. J., vol. 33, no. 3, pp. 315-335, Mar. 2012.

[19] R. C. Moussetis, A. Abu Rahma, and G. Nakos, "Strategic behavior and national culture: the case of the banking industry in Jordan," Compet. Rev., vol. 15, no. 2, pp. 101-115, Sep. 2005.

[20] J. B. Barney, "Is the Resource-Based 'View' a Useful Perspective for Strategic Management Research? Yes," Acad. Manag. Rev., vol. 26, no. 1, pp. 41-56, Jan. 2001.

[21] M. A. Peteraf and J. B. Barney, "Unraveling the resource-based tangle," Manag. Decis. Econ., vol. 24, no. 4, pp. 309-323, Jun. 2003.

[22] B. J. Jaworski and A. K. Kohli, "Market Orientation: Antecedents and Consequences," J. Mark., vol. 57, no. 3, p. 53, Jul. 1993.

[23] A. K. Kohli and B. J. Jaworski, "Market Orientation: The Construct, Research Propositions, and Managerial Implications," J. Mark., vol. 54, no. 2, p. 1, Apr. 1990.

[24] A. N. H. Oroh, "Does Synergy Mentality Mediate between Strategic Planning Relationship and a Firms Performance? An Empirical Study of Manufacturing Companies in Indonesia," Pertanika J. Soc. Sci. Hum., 2016.

[25] P. Brews and D. Purohi, "Strategic Planning in Unstable Environments," Long Range Plann., vol. 40, no. 1, pp. 64 - 83, 2007.

[26] T. Feng, T. Li, L. Sun, and D. Wang, "External involvement and operational 
performance," Chinese Manag. Stud., vol. 7, no. 3, pp. 488-507, Aug. 2013.

[27] R. A. Kerin and R. A. Peterson, Strategic Marketing Problems, Cases and Comments, 13th ed. New Jersey: Pearson, 2013. 